\title{
Personality Correlates of Self-Esteem
}

\author{
Richard W. Robins, Jessica L. Tracy, and Kali Trzesniewski \\ University of California, Davis
}

Jeff Potter

Brown University

and

\section{Samuel D. Gosling}

University of Texas, Austin

\begin{abstract}
The current study examined the relation between self-esteem and the Big Five personality dimensions. Data were collected over the Internet from a large heterogeneous sample of individuals who ranged in age from 9 to 90 years $(N=326,641)$. Collectively, the Big Five accounted for $34 \%$ of the variance in self-esteem. High self-esteem individuals were emotionally stable, extraverted, and conscientious and were somewhat agreeable and open to experience. Despite an extensive search for potential mediators and moderators of this general pattern, the relations between self-esteem and the Big Five largely cut across age, sex, social class, ethnicity, and nationality (United States vs non-United States). High self-esteem individuals tended to ascribe socially desirable traits to themselves, and this tendency partially mediated relations between the Big Five and self-esteem. Discussion focuses on interpreting the social desirability effects, limitations of the study, and directions for future research. () 2001 Academic Press
\end{abstract}

Researchers interested in individual differences in personality have generally relied on the five-factor model (FFM) as a framework for organizing the central constructs. Over the past couple of decades, studies have linked the Big Five dimensions to a wide range of other personality constructs (John \& Srivastava, 1999). During the same period, self-esteem researchers

This research was supported by a grant from the National Institute of Mental Health (MH61829) and by a Faculty Research Grant from the University of California, Davis. We thank Michelle R. Pryor for providing the social desirability ratings used in this study.

Address correspondence and reprint requests to Richard W. Robins, Department of Psychology, University of California, Davis, CA 95616-8686. E-mail: rwrobins@ucdavis.edu. 
have conducted thousands of studies examining the correlates, causes, and consequences of high and low self-esteem (Baumeister, 1993; Harter, 1998). Surprisingly, these two important lines of individual-difference research have rarely been connected. We know little about the personality characteristics that distinguish high versus low self-esteem individuals.

Understanding the relation between self-esteem and personality is important for several reasons. First, embedding self-esteem within the Big Five framework will link it to all other psychological constructs and outcomes that have been linked to the Big Five. The FFM provides a nomological network that helps to explain similarities and differences among variables. The Big Five dimensions of Extraversion, Agreeableness, Conscientiousness, Emotional Stability (vs. Neuroticism), and Openness to Experience (hereafter Openness) account for the interrelations among most trait terms (Goldberg, 1993b), and they are conceptualized at the broadest level that retains descriptive utility (John, Hampson, \& Goldberg, 1991). Possibly because of this breadth, the Big Five are relatively consistent over the life course (Roberts \& DelVecchio, 2000), generalize across many different cultures (McCrae \& Costa, 1997), and predict a wide range of outcomes including job performance (Barrick \& Mount, 1991), academic achievement (Robins, John, \& Caspi, 1998), delinquency (John, Caspi, Robins, Moffitt, \& Stouthamer-Loeber, 1994), personality disorders (Costa \& Widiger, 1994), adjustment (Graziano \& Ward, 1992), and divorce (Cramer, 1993). Connecting self-esteem to the Big Five will provide a basis for making predictions about how self-esteem might relate to the same set of outcomes and perhaps even offer clues to the mechanisms linking the Big Five to these outcomes.

Second, self-esteem and personality are likely to share common developmental roots, and examining the personality correlates of self-esteem across the life span might provide insights into the nature of self-esteem and its development. Like personality, self-esteem is moderately heritable, with about $30 \%$ of the variance due to genetic differences (Kendler, Gardner, \& Prescott, 1998). Basic temperamental characteristics, rooted largely in genetic differences, influence people's behavioral tendencies as well as their affective feelings about what kind of persons they are. For example, individuals with a temperamentally low threshold for the experience of negative affect tend to feel negatively about themselves (Watson \& Clark, 1984). Similarly, positive emotionality might lie at the core of both Extraversion and self-esteem (DeNeve \& Cooper, 1998). It seems likely, then, that self-esteem will be most strongly related to the two Big Five traits that have a clear affective component, namely Extraversion (positive affect) and Neuroticism (negative affect).

Third, in addition to sharing a common underlying etiology, self-esteem and personality may directly influence each other. For example, people's consistent patterns of behavior (i.e., personality) influence how they perceive 
and evaluate themselves. Conversely, self-esteem may play a critical role in shaping personality processes. Individuals' beliefs about themselves influence how they act in particular situations, the goals they pursue in life, how they feel about life events and relationship partners, and the ways in which they cope with and adapt to new environments. For example, a low selfesteem individual might lack the self-confidence to engage in a wide range of social behaviors and, consequently, become more introverted. Many prominent areas of personality research assume a central role for self-esteem and self-evaluations, including research on self-conscious emotions such as shame and embarrassment (e.g., Tangney \& Fischer, 1995), narcissism (e.g., Robins \& John, 1997), attachment (e.g., Shaver, Collins, \& Clark, 1996), self-defining memories (e.g., Singer \& Salovey, 1993), goals and motivation (e.g., Carver \& Scheier, 1998), and depression (Seligman, Abramson, Semmel, \& Von Baeyer, 1979).

Finally, the link between personality and self-esteem has implications for personality measurement. Most personality studies rely on self-report scales. When these scales are face valid, self-reports are closely tied to self-conceptions and self-evaluations. The underlying assumption is that what people think they are like will be related, albeit imperfectly, to what they are really like. Self-esteem has been defined as a global affective orientation toward the self, and high self-esteem individuals are likely to see themselves as possessing a wide range of socially desirable personality traits and as lacking undesirable traits. Thus, global self-esteem is conceptually related to socially desirable responding in personality assessment. These connections among social desirability, self-esteem, and personality raise the question of whether any of the relations between self-esteem and the Big Five dimensions can be accounted for by individual differences in social desirability.

\section{Previous Research}

Although no previous studies have focused on the relation between selfesteem and the Big Five, several studies have reported Big Five correlates of self-esteem. Table 1 provides a summary of these findings. Most of the studies used college student samples and found that self-esteem had a strong positive correlation with Emotional Stability, moderate positive correlations with Extraversion and Conscientiousness, and weak positive correlations with Agreeableness and Openness (Goldberg \& Rosolack, 1994; Jackson \& Gerard, 1996; Kwan, Bond, \& Singelis, 1997; Keller, 1999; Robins, Hendin, \& Trzesniewski, 2001). The two studies of adults found a similar pattern of correlations (Costa, McCrae, \& Dye, 1991; Pullman \& Allik, 1999). However, Graziano, Jensen-Campbell, and Finch (1997) found a somewhat different pattern in a sample of children ages 10 to 14 years. Most notably, the Big Five dimensions did not differ much in their correlations with self-esteem (all five correlations were between .28 and .39). This finding may reflect a 
ROBINS ET AL.

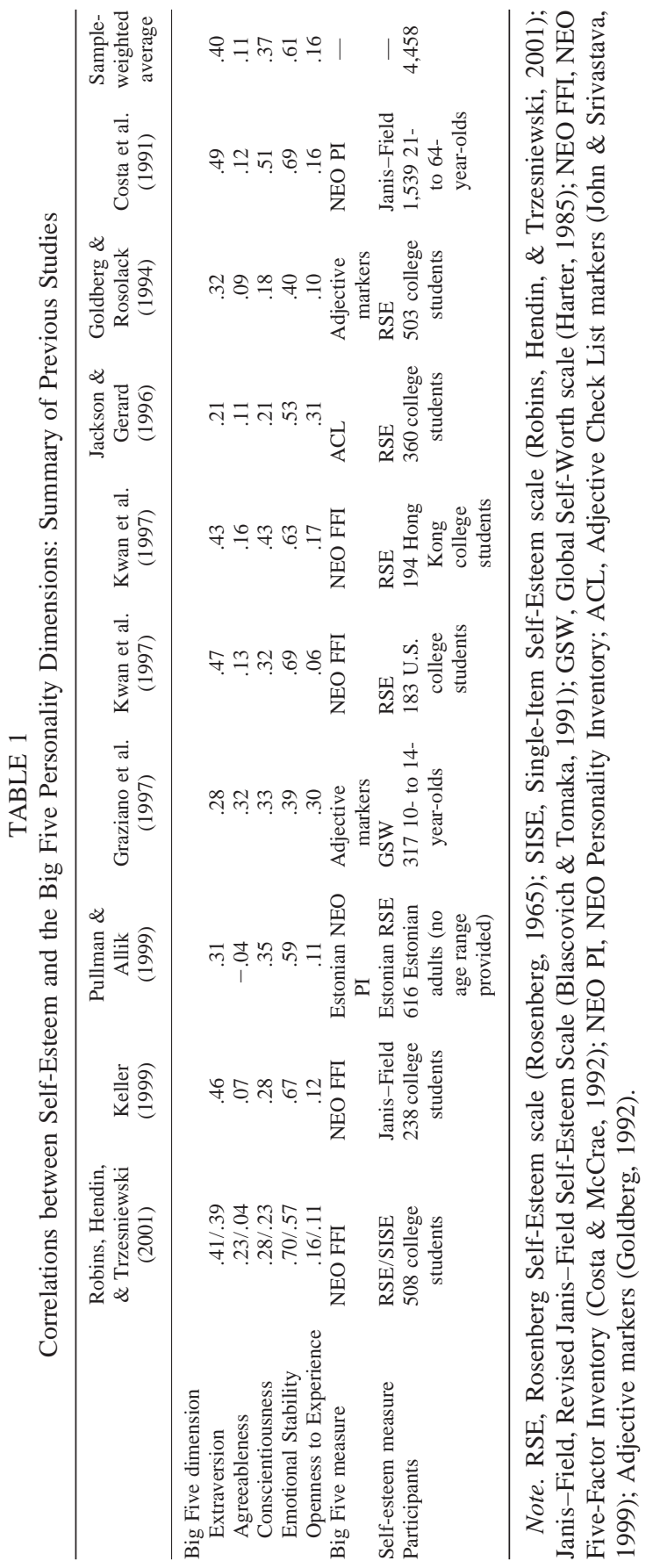


developmental shift in the structure of the self-concept; young children tend to view themselves similarly across different domains, and as they age their self-conceptions become more differentiated (Harter, 1998). Thus, the Big Five correlates of self-esteem may be somewhat different during childhood than during adulthood.

Previous research has not examined whether high self-esteem males and females have the same Big Five profile. However, previous research and theory suggests that agentic Big Five dimensions such as Extraversion and Conscientiousness might be more strongly related to self-esteem in males, whereas communal Big Five dimensions such as Agreeableness might be more strongly related to self-esteem in females (Block \& Robins, 1993). Other demographic variables such as ethnicity, socioeconomic status (SES), and nationality (United States vs non-United States) might also moderate the relation between self-esteem and personality. There is virtually no research on these issues and no clear theoretical basis for making predictions. The only existing relevant studies, Kwan et al.'s (1997) study of Hong Kong students and Pullman and Allik's (1999) study of Estonian adults, point to the generalizability of the Big Five correlates of self-esteem to non-U.S. populations.

Another issue concerns the influence of social desirability. Previous studies show that self-esteem is positively correlated with socially desirable Big Five traits such as Emotional Stability and Conscientiousness (see Table 1). This raises the possibility that the link between self-esteem and personality could be due in part to individual differences in the tendency to respond to the social desirability of personality items. In this sense, social desirability reflects a response style that confounds our understanding of the relation. However, from a theoretical perspective, it is difficult to disentangle style and substance, particularly in the context of self-esteem. To the extent that self-esteem reflects a person's global evaluation of his or her qualities, it follows that individuals with high self-esteem would also attribute desirable characteristics to themselves, either accurately or as a result of self-deception or impression management (Paulhus \& Reid, 1991). Although these issues have been discussed extensively in the context of the response style debate (e.g., Block, 1965; Edwards, 1970), the role of social desirability in the personality-self-esteem relation has not been explored.

Finally, previous studies of the relation between the Big Five and selfesteem have not explored more complex types of relations. Some of the Big Five dimensions may have interactive effects on self-esteem. For example, individuals high in Extraversion and Emotional Stability may have higher self-esteem than would be predicted from their individual effects. It is also possible that some of the relations between self-esteem and the Big Five are nonlinear (e.g., low self-esteem individuals might be particularly high or low on a trait). Thus, we will also test for the possibility that there are curvilinear relations between self-esteem and the Big Five. 
In summary, the existing research literature provides only a preliminary understanding of the relation between self-esteem and the Big Five. Several questions remain unanswered. Will the pattern previously found for college students hold for older and younger age groups? Do the Big Five correlates of self-esteem vary by sex, ethnicity, SES, and/or nationality? Does social desirability mediate any of the relations? Are there interactive or nonlinear relations between self-esteem and the Big Five?

The current study examined the personality correlates of self-esteem using data from a very large and diverse sample of individuals ranging in age from 9 to 90 years. The participants completed a questionnaire over the Internet that included measures of global self-esteem and the Big Five dimensions. Participants also provided information about their age, sex, ethnicity, nationality, and (for a subset) SES. Social desirability scores were computed based on social desirability ratings of the Big Five items. These variables were used as potential mediators and moderators of the Big Five correlates of selfesteem. The large sample size provided adequate power to test for interactive and nonlinear effects.

\section{METHOD}

\section{Participants and Procedure}

A total of 326,641 individuals (57\% women and $43 \%$ men) completed a questionnaire online by visiting an interactive Web site. ${ }^{1}$ The site was accessed either through a search engine $(46 \%)$, directly at its address $(27 \%)$, or through a link from another site $(27 \%)$. Links to the Web site were available on Web portals such as Yahoo, and information about the Web site was available on Usenet newsgroups and probably was spread by word of mouth as well. Participants logged onto the Internet using public Internet service providers (ISPs) (87\%), university ISPs $(10 \%)$, nonprofit organization ISPs $(2 \%)$, or government and military ISPs (1\%). Internet users who accessed the site were presented with a set of questions about their self-esteem and personality as well as some basic demographic questions (e.g., sex, age, ethnicity, national origin, state of residence, income, level of education). All questions were presented on the same Web page. Participants did not provide any personally identifying information, and complete anonymity was assured. The data used in the current study were drawn from the Gosling and Potter Internet Personality Data Set.

\section{Demographic Variables}

Participants ranged in age from 9 to 90 years $(M=24.0, S D=9.7)$. We grouped individuals into 10 age categories commonly used in developmental research: 9 to 12,13 to 17,18 to 22, 23 to 29, 30s, 40s, 50s, 60s, 70s, and 80s. The sample was diverse in terms of ethnicity (7\% Asian, 2\% Black, 78\% Caucasian, 2\% Chicano/Latino, 2\% Middle Eastern, 8\% missing/ multiracial/other) and nationality (67\% from the United States, $33 \%$ from more than 100 other countries). A subsample of 49,746 participants was asked to report their personal income in U.S. dollars (5\% below $\$ 12,000,3 \% \$ 12,000$ to $\$ 20,000,12 \% \$ 20,000$ to $\$ 30,000,26 \%$

${ }^{1}$ A total of 22,038 additional individuals completed the questionnaire but were excluded from the study because they did not report their age and/or sex. 
$\$ 30,000$ to $\$ 50,000,20 \% \$ 50,000$ to $\$ 70,000,18 \% \$ 70,000$ to $\$ 100,000,9 \% \$ 100,000$ to $\$ 150,000,3 \% \$ 150,000$ to $\$ 200,000,4 \%$ over $\$ 200,000)$ and their education level (30\% some high school, $12 \%$ high school diploma, $31 \%$ some college, $20 \%$ college degree, $7 \%$ graduate degree). ${ }^{2}$ To assess SES, income and education level were standardized and then composited.

\section{Self-Esteem}

Self-esteem was measured using the Single-Item Self-Esteem scale (SISE) (Robins, Hendin, \& Trzesniewski, 2001). Participants rated the item, "I see myself as someone who has high self-esteem," on a 5-point Likert scale ranging from 1 (strongly disagree) to 5 (strongly agree $)$. In the current sample, the SISE had a mean of $3.39(S D=1.31)$. Robins et al. provided extensive validation data for the SISE. In three studies, disattenuated correlations between the SISE and the Rosenberg (1965) Self-Esteem (RSE) scale approached 1.00 (disattenuated correlations ranged from .91 to .99 , whereas correlations ranged from .74 to .80). This strong convergent validity held for males and females, for different ethnic groups, for different occupational statuses, for college students and community members, and for individuals ranging in age from 17 to 61 years. Moreover, the SISE and the RSE had nearly identical correlations with 37 different criteria including domain-specific self-evaluations, self-evaluative biases, social desirability, the Big Five personality dimensions, psychological and physical health, peer ratings of group behavior, demographic characteristics, and several academic outcomes. Robins et al. also found that the SISE had moderate convergent validity during childhood; the SISE correlated .51 with the RSE in one sample (ages 10-13 years) and .52 with the Harter (1985) Global Self-Worth scale in another sample (ages 9-13 years). Using longitudinal data, Robins et al. estimated the reliability of the SISE to be 75 (Heise, 1969). Robins, Trzesniewski, Tracy, Gosling, and Potter (2001) reported age and sex differences in self-esteem for the current sample.

\section{Personality}

The Big Five personality dimensions were assessed using the 44-item Big Five Inventory (BFI) (John \& Srivastava, 1999). The BFI shows high convergent validity with other selfreport scales and with peer ratings of the Big Five. The BFI items were rated on a 5-point Likert scale ranging from 1 (strongly disagree) to 5 (strongly agree). In the current sample, alpha reliabilities were .85 for Extraversion, .79 for Agreeableness, .82 for Conscientiousness, .83 for Emotional Stability, and .78 for Openness. These values are as high as those reported for paper-and-pencil administrations of the BFI (John \& Srivastava, 1999). Scale means in the current sample were $3.24(S D=0.88)$ for Extraversion, $3.59(S D=0.73)$ for Agreeableness, $3.38(S D=0.75)$ for Conscientiousness, $3.05(S D=0.87)$ for Emotional Stability, and

\footnotetext{
${ }^{2}$ These data were available for only a subsample of participants because questions about income and education level were included on the Web site for a limited period of time. Unfortunately, the Web site did not include an option that specified an education level less than "some high school.' Many participants in the youngest age groups left this question blank. However, we suspect that the younger participants who did respond probably decided to simply click on the option with the lowest education level (the vast majority of responses were for "some high school',). Likewise, many of the younger participants probably responded to the question about income by reporting on their parents' income. Given these considerations, the meaning of the SES variable is ambiguous for the participants in the three youngest age groups (9$12,13-17$, and 18-22 years). Thus, we excluded these three age groups and reran all of the analyses involving SES. In all cases, the findings remained the same and the magnitude of the effects changed only slightly.
} 
$3.94(S D=0.65)$ for Openness. Srivastava, John, Gosling, and Potter (2001) reported age and sex differences in the Big Five for the current sample.

\section{Social Desirability Ratings of the Big Five}

A total of 15 judges ( 8 women and 7 men) independently rated the social desirability of each BFI item. Judges were college students ranging in age from 17 to 33 years (median = 22). The directions stated, "Descriptors of people often contain evaluative information. Some characteristics are considered socially desirable, whereas others are undesirable. We would be interested to learn how desirable you consider each of the following characteristics." Ratings were made on a 9-point Likert scale ranging from 1 (extremely undesirable) to 9 (extremely desirable), with 4 as neutral. These ratings were highly reliable (coefficient alpha $=$ .97) and were composited across judges for each item. To compute social desirability scores, we multiplied the social desirability rating for each BFI item by the participant's rating of each item. These weighted values were then aggregated across all 44 items. The resulting social desirability scores correlated .33 with self-esteem, indicating that individuals with high self-esteem tend to endorse socially desirable items.

\section{RESULTS}

The results are presented in three sections. In the first section, we report the zero-order correlations between self-esteem and the Big Five personality dimensions and examine the mediating effects of social desirability and sex. In the second section, we report the results of multiple regression analyses testing the independent, interactive, and nonlinear effects of the Big Five on self-esteem. In the third section, we examine whether age, sex, SES, ethnicity, and/or nationality moderate the relations between self-esteem and the Big Five. Given the extremely large sample size, we focus on the magnitude of the effects rather than on their statistical significance.

\section{Correlations between the Big Five and Self-Esteem}

Table 2 shows correlations between self-esteem and each of the Big Five dimensions, separately for the total sample and by sex. Self-esteem correlated positively with Extraversion ( $r=.38$ ), Agreeableness $(r=.13)$, Conscientiousness $(r=.24)$, Emotional Stability $(r=.50)$, and Openness $(r=$ .17). Both the pattern and the magnitude of these correlations are consistent with those found in previous studies (see Table 1). The largest discrepancies from previous research were for Conscientiousness (sample-weighted mean in previous studies $=.37$ ) and Emotional Stability (sample-weighted mean $=.61)$.

Overall, the findings suggest that high self-esteem individuals possess socially desirable traits. It is possible, then, that the Big Five correlations reflect the tendency of high self-esteem individuals to endorse socially desirable items. To test this, we computed partial correlations between self-esteem and the Big Five, controlling for the social desirability scores (see Table 2). The correlations with Extraversion, Conscientiousness, and Emotional Stability were reduced slightly, but the most noticeable change was the elimination 
TABLE 2

Correlations between Self-Esteem and the Big Five Dimensions by Gender

\begin{tabular}{lccc}
\hline & $\begin{array}{c}\text { Total sample } \\
(n=326,641)\end{array}$ & $\begin{array}{c}\text { Females } \\
(n=186,392)\end{array}$ & $\begin{array}{c}\text { Males } \\
(n=140,249)\end{array}$ \\
\hline Extraversion & .38 & .38 & .42 \\
Agreeableness & $(.31)$ & $(.30)$ & $(.34)$ \\
Conscientiousness & .13 & .14 & .13 \\
& $(.00)$ & $(.02)$ & $.01)$ \\
Emotional Stability & .24 & .22 & .29 \\
& $(.15)$ & $(.13)$ & .48 \\
Openness to Experience & .50 & .50 & $(.45)$ \\
& $(.46)$ & $(.45)$ & .18 \\
& .17 & .16 & $(-.05)$ \\
\hline
\end{tabular}

Note. Partial correlations controlling for social desirability are in parentheses.

of the Agreeableness and Openness correlations. This suggests that high selfesteem individuals might not be more agreeable and open to new experiences when their general tendency to endorse socially desirable items is taken into account.

Men reported higher self-esteem than did women $(d=.22)$, which raises the possibility that sex might mediate some of the relations between the Big Five and self-esteem. However, the partial correlations between self-esteem and the Big Five (controlling for sex) were almost identical to the zero-order correlations: . 40 for Extraversion, .14 for Agreeableness, .25 for Conscientiousness, .49 for Emotional Stability, and .17 for Openness.

\section{Effects of the Big Five on Self-Esteem}

Independent effects. To examine the independent effects of the Big Five on self-esteem, we conducted a multiple regression analysis in which selfesteem was predicted by all five dimensions. Collectively, the Big Five accounted for $34 \%$ of the variance in self-esteem. Thus, the Big Five are important predictors of self-esteem but do not account for the majority of the variance. Consistent with the zero-order correlations, Emotional Stability $(\beta=.41)$ and Extraversion $(\beta=.26)$ had the largest effects, followed by Conscientiousness $(\beta=.13)$ and Openness $(\beta=.08)$. The effect of Agreeableness changed from positive to slightly negative $(\beta=-.06)$. Adding social desirability to the equation produced minor changes in the $\beta$ weights. The Emotional Stability effect $(\beta=.41)$ stayed the same, the Extraversion $(\beta=.22)$ and Conscientiousness effects $(\beta=.08)$ were slightly weaker, the Agreeableness effect $(\beta=-.11)$ was slightly stronger, and the Openness effect $(\beta=-.02)$ became slightly negative. 
Interaction effects. To test for interactions among the Big Five, we conducted a series of moderated multiple regression analyses. We tested for all possible two-, three-, four-, and five-way interactions. None of the interaction terms accounted for more than a trivial proportion of variance $\left(R^{2} \Delta<1 \%\right)$. Thus, interactions among the Big Five dimensions did not predict self-esteem above and beyond their independent effects.

Nonlinear effects. To examine nonlinear effects, we conducted a series of hierarchical multiple regression analyses that included each Big Five dimension as a quadratic function (i.e., we standardized and squared each dimension). In each analysis, we entered a Big Five dimension and then its quadratic term in the second step. None of the five quadratic effects accounted for more than $1 \%$ of the variance in self-esteem, suggesting that there are no curvilinear relations between the Big Five and self-esteem.

\section{Moderators of the Relation between the Big Five and Self-Esteem}

Sex differences. Overall, the correlations between self-esteem and the Big Five were highly similar for men and women (see Table 2). The interaction between sex and each of the Big Five dimensions accounted for less than $1 \%$ of the variance. However, the weak sex differences were consistent with our expectations about the importance of agentic traits (e.g., Extraversion) for men's self-esteem and communal traits (e.g., Agreeableness) for women's self-esteem. The correlations with Extraversion, Conscientiousness, and Openness were slightly stronger for men, and the correlations with Agreeableness and Emotional Stability were slightly stronger for women. These effects, although very small, were quite robust in some cases. The sex differences in the self-esteem correlates of Extraversion and Conscientiousness held across the life span (except for individuals in their 70s), for all five ethnicities, for high and low SES participants, and for U.S. and non-U.S. participants.

Age differences. Table 3 shows correlations between self-esteem and the Big Five dimensions by age group. Within every age group, self-esteem correlated positively with all five dimensions. In addition, throughout most of the life span (ages 13-69 years), the two Big Five traits most strongly correlated with self-esteem were first Emotional Stability and then Extraversion. The moderating effect of age was statistically examined using moderated multiple regression. The interactions between age and the Big Five accounted for less than $1 \%$ of the variance for all five dimensions. These interaction effects test for linear changes in the relation between self-esteem and the Big Five across the entire age range. They would not necessarily detect shifts in the relations in specific age periods, particularly when the moderator variable (age) is extremely skewed.

Inspection of Table 3 shows several moderately large age differences that were specific to the two oldest age groups. For example, the correlation be- 





tween self-esteem and Emotional Stability was substantially weaker in old age, particularly in the 80- to 90-year age group $(r=.13)$. In fact, self-esteem correlated more strongly with Extraversion than with Emotional Stability in the 70- to 79-year and 80- to 90-year age groups. Furthermore, Openness, which throughout the life span showed only moderate correlations with selfesteem ( $r$ s ranging from .13 to .30), was highly correlated during old age ( $r=.47$ for ages 70-79 years and .53 for ages 80-90 years), although as we noted earlier, this relation was mediated by social desirability. Finally, the results in the youngest age group were consistent with Graziano et al.'s (1997) finding that the Big Five correlates of self-esteem tend to be less differentiated during childhood ( $r$ s ranged from .22 to .36 for ages 9-12years, whereas the range in the total sample was from .13 to .50).

Ethnicity, SES, and nationality. The general pattern of zero-order correlations between self-esteem and the Big Five dimensions found for the whole sample held for all ethnicities examined, for both high and low SES participants, and for both U.S. and non-U.S. participants (see Table 4). That is, across all ethnic, SES, and nationality groups, self-esteem correlated most strongly with Emotional Stability and then Extraversion, moderately with Conscientiousness, and weakly with Openness and Agreeableness.

The moderating effects of SES and nationality were statistically examined by conducting moderated multiple regression analyses. None of the interaction effects accounted for more than $1 \%$ of the variance. To test for ethnic differences in the Big Five correlates, we used structural equation modeling (SEM). SEMs were conducted on covariance matrices using LISREL 8.30 (Jöreskog \& Sörbom, 1996). Specifically, we tested a model in which the paths between self-esteem and each of the Big Five dimensions were constrained to be equal across all five ethnic groups. The results showed that the model of total invariance fit the data well, $\chi^{2}(N=326,641, d f=20)=$ 661.17, RMSEA $=.02, C F I=1.00, N F I=1.00, N N F I=.99$. These results suggest that the Big Five correlates of self-esteem do not vary by ethnicity.

\section{DISCUSSION}

The current study established the basic personality profile of high and low self-esteem individuals using a large heterogeneous sample. High selfesteem individuals tend to be Extraverted, Agreeable, Conscientious, Emotionally Stable, and Open to Experience. Despite an extensive search for potential mediators and moderators of this general pattern, and despite more than adequate statistical power, the relations between self-esteem and the Big Five largely cut across age, sex, SES, ethnicity, and nationality.

Although the overall pattern of correlations was consistent across demographic groups, there were several sex and age differences that warrant discussion and further examination. The weak sex differences were in the direction expected from previous research and theory. For example, the cor- 


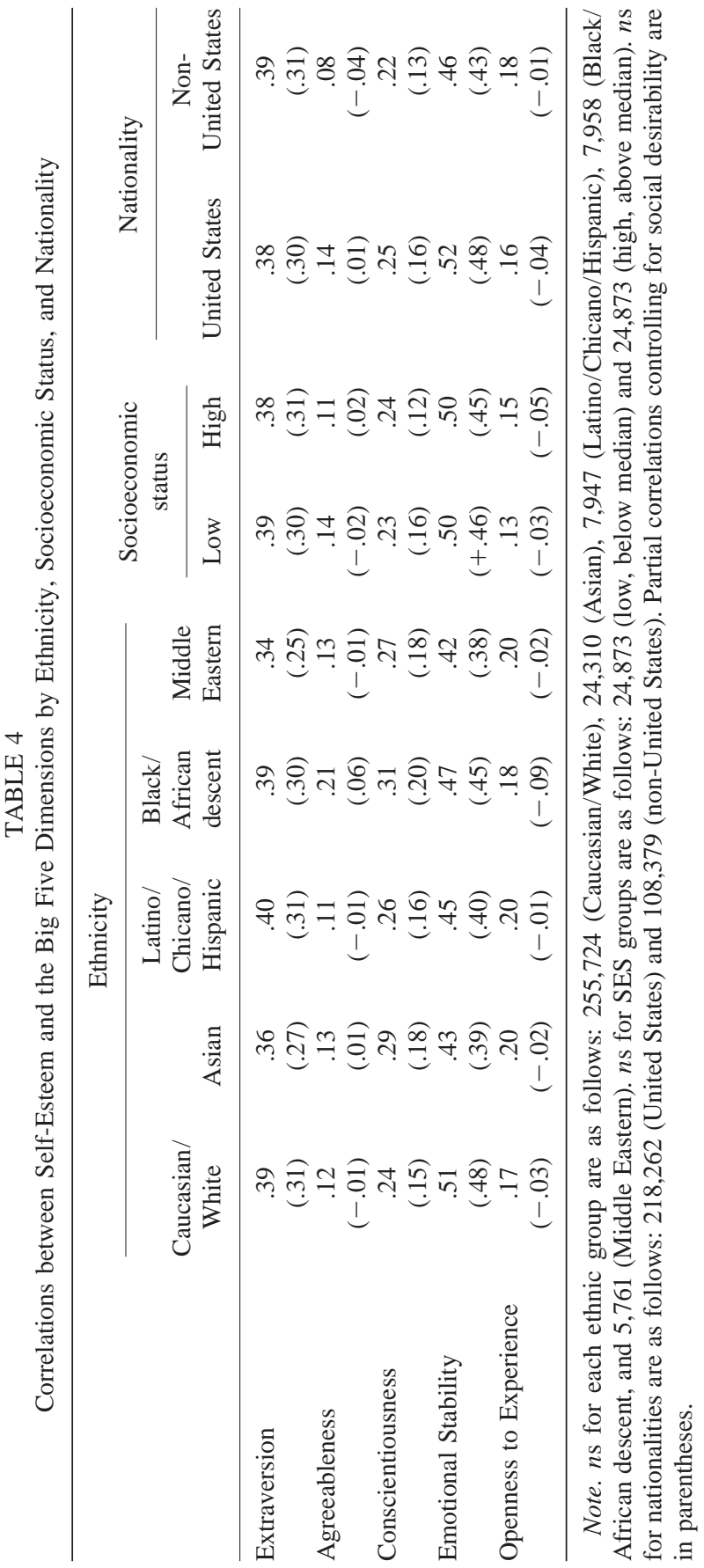


relation with Extraversion (which includes assertiveness and dominance) was slightly stronger for men, and the correlation with Agreeableness (which includes nurturing and affiliative traits) was slightly stronger for women. This pattern suggests that the presence of gender-stereotypical traits may influence the development of self-esteem. Specifically, communal traits promote high self-esteem in women, whereas agentic traits promote high selfesteem in men, perhaps because communal women and agentic men are better able to meet the cultural press of gender role standards and expectations.

In addition, although the Big Five correlates of self-esteem were similar across most of the life span, the basic pattern diverged somewhat for individuals aged 70 to 90 years. In the two oldest age groups, the correlations with Extraversion, Agreeableness, Conscientiousness, and Openness were generally stronger than at any other time during the life course. This age difference may reflect the increased importance of these traits for maintaining and creating positive social bonds and for seeking out new and challenging situations that promote feelings of mastery. Traits such as Extraversion and Openness may also protect against loneliness because they facilitate finding and enjoying new interests. In contrast to the other four dimensions, the correlation with Emotional Stability was much weaker in the oldest age groups. It may be that self-esteem during old age is based less on current feelings of negative affect and more on a lifetime of accomplishments and experiences.

Social desirability was the only variable that substantially affected the relations between self-esteem and the Big Five. Although the strongest correlates of self-esteem (Extraversion, Conscientiousness, and Emotional Stability) changed only slightly after controlling for socially desirable responding, the weaker correlates (Agreeableness and Openness) all but disappeared. The effects of partialling out social desirability held across the various demographic groups. This finding is important for two main reasons. First, the fact that the strongest correlations were not mediated by social desirability indicates that the links between self-esteem and these traits are due to more than just response style. Second, the fact that some of the Big Five correlates were mediated by social desirability indicates that the social desirability of item content does account for some of the overlap between self-esteem and personality.

It is not clear, however, whether these mediated effects reflect substance or style. An important question raised by the current study is whether high self-esteem individuals actually have more socially desirable traits. Are these individuals as sociable, kind, responsible, emotionally stable, and creative as they report? If so, then partialling out social desirability may be akin to throwing out the baby with the bathwater. On the other hand, high selfesteem individuals may be intentionally hiding their personality flaws and inflating their virtues, or they may be responding honestly but are selfdeceived about their true personality characteristics. If either self-deception 
or intentional self-presentation is occurring, then partialling out social desirability may more accurately reflect the "true" personality correlates of selfesteem.

Another implication of the mediating influence of social desirability, and its correlation with self-esteem $(r=.33)$, is that social desirability and selfesteem might derive from similar underlying self-evaluation processes, for example, self-enhancement tendencies. In this sense, self-esteem and social desirability may be conceptually inseparable. On the other hand, although both constructs clearly involve ascribing positive characteristics to the self, some self-esteem theorists have argued that global self-esteem is more than just a summation of a person's evaluations of his or her individual attributes. For example, high self-esteem may derive from a more generalized abstract feeling of self-worth (Coopersmith, 1967). Clarifying these issues will help us to understand the role of social desirability in the self-esteem and personality relation.

The current study has several limitations that warrant discussion. First, the measure of self-esteem used in this study, the SISE, has not been validated as extensively as has the RSE, which is the most widely used self-esteem scale. However, Robins et al. (2001) showed that the SISE and the RSE have very similar Big Five correlates and share nearly all of their reliable variance (disattenuated correlations approached unity). Moreover, the pattern of correlates found in the current study is consistent with previous research using the RSE (see Table 1). Together, all of this suggests that the findings would have been highly similar if we had used the RSE, instead of the SISE, to measure self-esteem.

Second, one distinctive feature of the current study is that the data were collected over the Internet. This provides several advantages relative to previous studies in this area. In particular, the very large sample size provides substantial statistical power to explore complex relations and a sufficient number of participants in each demographic group to compare findings across sex, age, ethnicity, SES, and nationality. Moreover, the heterogeneity of the sample relative to previous studies strengthens the potential generalizability of our findings. At the same time, the Internet method of data collection also raises concerns about the representativeness of the sample. Most notably, the current sample is necessarily limited to individuals who have access to and use the Internet and to those who choose to complete the questionnaire online. Although Internet users may be no more select a sample than those who typically participate in psychological research, some caution is warranted given the currently limited information about Internet-based studies (Buchanan \& Smith, 1999). Thus, one important direction for future research is to replicate the current findings using a randomly selected, representative sample of individuals. This would greatly increase the generalizability of our conclusions and alleviate concerns about the Internet sample. 
Third, the social desirability effects raise a few conceptual issues that require further research. In particular, the question of whether high selfesteem individuals really possess desirable traits suggests the need for nonself-report measures of the Big Five. If peers, spouses, psychologists, and others confirm that high self-esteem individuals possess the rosy personality profiles that they self-report, then this would indicate that the relations found here are not based simply on biased self-views.

Another way of addressing this issue would be to use a social desirability measure that assesses both self-deceptive enhancement and impression management (e.g., Paulhus, 1994). ${ }^{3}$ This would help to distinguish narcissistic individuals, who are prone to self-deceptive enhancement, from individuals who engage in self-presentation and, thus, are prone to impression management. Research on narcissism suggests that some individuals who report high self-esteem may in fact be self-aggrandizing to defend against their implicit feelings of inadequacy. Thus, the personality correlates of self-esteem may be biased by narcissistic tendencies. To explore this issue, we reanalyzed data from Robins et al. (2001). We computed partial correlations between self-esteem (measured with the SISE) and the Big Five (measured with the NEO Five-Factor Inventory [NEO FFI]), controlling for narcissism (measured with the Narcissistic Personality Inventory). The partial correlations with Extraversion, Emotional Stability, and Openness were slightly weaker ( $r \mathrm{~s}=.29, .54$, and .05 , respectively) than the zero-order correlations (see the first column of Table 1), suggesting that these effects are partially mediated by narcissism. In contrast, the partial correlations with Agreeableness and Conscientiousness became even stronger. Controlling for narcissism increased the correlation between self-esteem and Agreeableness from .04 to .22 and increased the correlation with Conscientiousness from .23 to .25. This suggests that narcissism has a suppressor effect on these relations. It is possible, then, that self-report biases, as reflected in narcissistic tendencies, may conceal relations between self-esteem and the "moralistic" aspects of the Big Five (Paulhus \& John, 1998). By statistically "eliminating", the subset of high self-esteem individuals who are narcissistic, we see that high selfesteem individuals may be somewhat more friendly and responsible than our findings suggest.

Another future direction would be to explicate the relation between selfesteem and the Big Five at a more specific level. The Big Five are broad domains that subsume narrower facets (e.g., Costa \& McCrae, 1995; Gold-

\footnotetext{
${ }^{3}$ Robins et al. (2001, Study 2) reported correlations between the SISE and the two social desirability scales on Paulhus's (1994) Balanced Inventory of Desirable Responding. The SISE correlated .21 with the Self-Deceptive Enhancement scale and .04 with the Impression Management scale. The RSE had similar correlations with these two scales (.22 and .13 , respectively).
} 
berg, 1993a). For example, Costa and McCrae (1995) specified six facet scales for each Big Five dimension on their NEO Personality Inventory (NEO PI). Determining how self-esteem relates to these specific scales will provide a more nuanced understanding of the personality correlates of selfesteem. Self-esteem may be better represented by combinations of Big Five facets than by the broad domains. Global self-esteem can also be broken down into facets. Some researchers emphasize domain-specific self-evaluations such as academic and social self-esteem (e.g., Coopersmith, 1967; Harter, 1985), whereas others emphasize conceptual distinctions such as selfliking and self-competence (e.g., Tafarodi \& Swann, 1995). These different aspects of self-evaluation are likely to have different Big Five correlates. For example, academic self-esteem and self-competence should be more strongly related to Conscientiousness than should social self-esteem and self-liking.

The current findings show that high self-esteem individuals can be described in terms of a particular set of Big Five traits. This raises the question of whether self-esteem can be entirely subsumed within the Big Five framework. From the current data, we know that the Big Five dimensions collectively account for only $34 \%$ of the variance of self-esteem, indicating that $66 \%$ of the variance remains (although some of the remaining variance is measurement error). Nonetheless, it is still possible that the Big Five can account for some previous self-esteem findings. For example, numerous studies have demonstrated that self-esteem is related to constructs such as feedback seeking, causal attributions, social comparisons, depression, achievement, personal memories, and relationship behaviors. Do these relations exist independently of the Big Five? That is, would self-esteem still predict these variables if the Big Five were partialled out of the relation? Even if this turns out to be the case, it is important to note that theory and research on self-esteem would still be necessary to understand the relations. Accounting for variance in a phenomenon is not the same as explaining it.

Finally, the current findings do not allow us to disentangle the causal direction of the relation between self-esteem and the Big Five. That is, we do not know whether a particular Big Five profile engenders high self-esteem; whether high self-esteem promotes certain cognitive, behavioral, and affective tendencies that are captured by particular Big Five dimensions; or both. According to McCrae and Costa's (1999) five-factor theory, the Big Five dimensions influence people's self-conceptions, but self-conceptions do not influence the Big Five, which are determined exclusively by biological factors. This is an important assumption that should be tested empirically. For example, a longitudinal study that measures change in the Big Five and self-esteem over time would help to clarify the causal relation. A related issue is identifying the mechanisms that mediate the link between self-esteem and personality. For example, if self-esteem influences personality, then how might high self-esteem translate into the set of prosocial and adaptive behav- 
iors captured by the Big Five correlates? Similarly, if personality influences self-esteem, then how might Extraversion and Emotional Stability result in positive feelings of self-worth? The answers to such questions get at the heart of the relation between self and personality and will illuminate research in both areas.

\section{REFERENCES}

Barrick, M. R., \& Mount, M. K. (1991). The Big Five personality dimensions and job performance: A meta-analysis. Personnel Psychology, 44, 1-26.

Baumeister, R. F. (1993). Self-esteem: The puzzle of low self-regard. New York: Plenum.

Blascovich, J., \& Tomaka, J. (1991). Measures of self-esteem. In J. P. Robinson, P. R. Shaver, \& L. S. Wrightsman (Eds.), Measures of personality and social psychological attitudes (pp. 115-160). San Diego: Academic Press.

Block, J. (1965). The challenge of response sets: Unconfounding meaning, acquiescence, and social desirability in the MMPI. New York: Appleton-Century-Crofts.

Block, J., \& Robins, R. W. (1993). A longitudinal study of consistency and change in selfesteem from early adolescence to early adulthood. Child Development, 64, 909-923.

Buchanan, T., \& Smith, J. L. (1999). Using the Internet for psychological research: Personality testing on the World Wide Web. British Journal of Psychology, 90, 125-144.

Carver, C. S., \& Scheier, M. F. (1998). On the self-regulation of behavior. New York: Cambridge Univ. Press.

Coopersmith, S. (1967). The antecedents of self-esteem. San Francisco: Freeman.

Costa, P. T., \& McCrae, R. R. (1995). Domains and facets: Hierarchical personality assessment using the Revised NEO Personality Inventory. Journal of Personality Assessment, 64, 21-50.

Costa, P. T., McCrae, R. R., \& Dye, D. A. (1991). Facet scales for Agreeableness and Conscientiousness: A revision of the NEO Personality Inventory. Personality and Individual Differences, 12, 887-898.

Costa, P. T., \& Widiger, T. A. (Eds.). (1994). Personality disorders and the five-factor model of personality. Washington, DC: American Psychological Association.

Cramer, D. (1993). Personality and marital dissolution. Personality and Individual Differences, 14, 605-607.

DeNeve, K. M., \& Cooper, H. (1998). The happy personality: A meta-analysis of 137 personality traits and subjective well-being. Psychological Bulletin, 124, 197-229.

Edwards, A. L. (1970). The measurement of personality traits by scales and inventories. New York: Holt, Rinehart \& Winston.

Goldberg, L. R. (1992). The development of markers for the Big-Five factor structure. Psychological Assessment, 4, 26-42.

Goldberg, L. R. (1993a). The structure of personality traits: Vertical and horizontal aspects. In D. C. Funder, R. D. Parke, C. Tomlinson-Keasey, \& K. Widaman (Eds.), Studying lives through time: Personality and development (pp. 169-188). Washington, DC: American Psychological Association.

Goldberg, L. R. (1993b). The structure of phenotypic personality traits. American Psychologist, 48, 26-34.

Goldberg, L. R., \& Rosolack, T. K. (1994). The Big Five factor structure as an integrative framework: An empirical comparison with Eysenck's PEN model. In C. F. Halverson, 
G. A. Kohnstamm, \& R. P. Martin (Eds.), The developing structure of temperament and personality from infancy to adulthood (pp. 7-35). Hillsdale, NJ: Erlbaum.

Graziano, W. G., Jensen-Campbell, L. A., \& Finch, J. F. (1997). The self as a mediator between personality and adjustment. Journal of Personality and Social Psychology, 73, 392-404.

Graziano, W. G., \& Ward, D. (1992). Probing the Big Five in adolescence: Personality and adjustment during a developmental transition. Journal of Personality, 60, 425-429.

Harter, S. (1985). Manual for the Self-Perception Profile for Children (revision of the Perceived Competence Scale for Children). Denver, CO: Univ. of Denver Press.

Harter, S. (1998). The development of self-representations. In W. Damon \& N. Eisenberg (Eds.), Handbook of child psychology (pp. 553-617). New York: Wiley.

Heise, D. R. (1969). Separating reliability and stability in test-retest correlation. American Sociological Review, 34, 93-101.

Jackson, L. A., \& Gerard, D. A. (1996). Diurnal types, the "Big Five", personality factors, and other personal characteristics. Journal of Social Behavior and Personality, 11, 273283.

John, O. P., Caspi, A., Robins, R. W., Moffitt, T. E., \& Stouthamer-Loeber, M. (1994). The "little five": Exploring the nomological network of the five-factor model of personality in adolescent boys. Child Development, 65, 160-178.

John, O. P., \& Srivastava, S. (1999). The Big Five trait taxonomy: History, measurement, and theoretical perspectives. In L. A. Pervin \& O. P. John (Eds.), Handbook of personality: Theory and research (2nd ed., pp. 102-138). New York: Guilford.

Jöreskog, K., \& Sörbom, D. (1996). LISREL 8: User's reference guide. Chicago: Scientific Software International.

Keller, T. (1999). Images of the familiar: Individual differences and implicit leadership theories. The Leadership Quarterly, 10, 589-607.

Kendler, K. S., Gardner, C. O., \& Prescott, C. A. (1998). A population-based twin study of self-esteem and gender. Psychological Medicine, 28, 1403-1409.

Kwan, V. S. Y., Bond, M. H., \& Singelis, T. M. (1997). Pancultural explanations for life satisfaction: Adding relationship harmony to self-esteem. Journal of Personality and Social Psychology, 73, 1038-1051.

McCrae, R. R., \& Costa, P. T. (1997). Personality trait structure as a human universal. American Psychologist, 52, 509-516.

McCrae, R. R., \& Costa, P. T. (1999). A five-factor theory of personality. In L. A. Pervin \& O. P. John (Eds.), Handbook of personality: Theory and research (pp. 139-153). New York: Guilford.

Paulhus, D. L. (1994). Reference manual for the Balanced Inventory of Desirable Responding, Version 6. Vancouver: University of British Columbia, Department of Psychology.

Paulhus, D. L., \& John, O. P. (1998). Egoistic and moralistic biases in self-perception: The interplay of self-deceptive styles with basic traits and motives. Journal of Personality, 66, 1025-1060.

Paulhus, D. L., \& Reid, D. B. (1991). Enhancement and denial in socially desirable responding. Journal of Personality and Social Psychology, 60, 307-317.

Pullmann, H., \& Allik, J. (2000). The Rosenberg Self-Esteem Scale: Its dimensionality, stability and personality correlates in Estonian. Personality and Individual Differences, 28, $701-715$.

Roberts, B. W., \& DelVecchio, W. F. (2000). The rank-order consistency of personality traits 
from childhood to old age: A quantitative review of longitudinal studies. Psychological Bulletin, 126, 3-25.

Robins, R. W., Hendin, H. M., \& Trzesniewski, K. H. (2001). Measuring global self-esteem: Construct validation of a single item measure and the Rosenberg Self-Esteem scale. Personality and Social Psychology Bulletin, 27, 151-161.

Robins, R. W., \& John, O. P. (1997). Effects of visual perspective and narcissism on selfperception: Is seeing believing? Psychological Science, 8, 37-42.

Robins, R. W., John, O. P., \& Caspi, A. (1998). The typological approach to studying personality development. In R. B. Cairns, L. Bergman, \& J. Kagan (Eds.), Method and models for studying the individual (pp. 135-160). Thousand Oaks, CA: Sage.

Robins, R. W., Trzesniewski, K. H., Tracy, J. L., Gosling, S. D., \& Potter, J. (2001). Selfesteem across the lifespan. Manuscript submitted for publication.

Rosenberg, M. (1965). Society and the adolescent self-image. Princeton, NJ: Princeton Univ. Press.

Seligman, M. E. P., Abramson, L. Y., Semmel, A., \& Von Baeyer, C. (1979). Depressive attributional style. Journal of Abnormal Psychology, 88, 242-247.

Shaver, P. R., Collins, N., \& Clark, C. L. (1996). Attachment styles and internal working models of self and relationship partners. In G. J. O. Fletcher \& J. Fitness (Eds.), Knowledge structures in close relationships: A social psychological approach (pp. 25-61). Mahwah, NJ: Erlbaum.

Singer, J. A., \& Salovey, P. (1993). The remembered self: Emotion and memory in personality. New York: Free Press.

Srivastava, S., John, O. P., Gosling, S. D., \& Potter, J. (2001). Personality across adulthood: Age, gender, and the Big Five. Manuscript submitted for publication.

Tafarodi, R. W., \& Swann, W. B., Jr. (1995). Self-liking and self-competence as dimensions of global self-esteem: Initial validation of a measure. Journal of Personality Assessment, 65, 322-342.

Tangney, J. P., \& Fischer, K. W. (Eds.). (1995). Self-conscious emotions: The psychology of shame, guilt, embarrassment, and pride. New York: Guilford.

Watson, D., \& Clark, L. A. (1984). Negative affectivity: The disposition to experience aversive emotional states. Psychological Bulletin, 96, 465-490. 